DOI:

http://dx.doi.org/10.15448/1983-4012.2015.2.18516

\title{
A ALTERNATIVA FUNDACIONISTA DE BONJOUR
}

BonJour's foundationalist alternative

Jonatan Willian Daniel *

Resumo: O objetivo deste trabalho é avaliar a solução fundacionista proposta por Laurence BonJour para o problema do regresso epistêmico. De acordo com BonJour, a consciência não aperceptiva constitutiva do conteúdo de um estado consciente atual justificaria uma crença aperceptiva acerca desse estado mental. Essa consciência, no que se refere a percepções sensoriais, cumpriria o papel de elemento básico do conhecimento exigido pelos fundacionistas para a solução do problema do regresso epistêmico. A avaliação dessa concepção é particularmente interessante porque BonJour endossou por muito tempo a crítica sellarsiana ao fundacionismo, e nos textos aqui analisados pretende defender uma forma de fundacionismo imune às críticas de Sellars. Neste trabalho, argumento que a solução fundacionista proposta por BonJour não alcança seu objetivo. Nossa análise (1) avalia se a descrição de BonJour do que é entreter uma crença ocorrente é adequada fenomenologicamente, (2) analisa em que sentido é possível comparar um conteúdo sem forma proposicional - como o de uma experiência sensorial - e um conteúdo proposicional da crença aperceptiva que a descreve e (3) avalia se a cognição do ajuste da descrição proposicional de um conteúdo sensorial não implica uma crença contingente de que tal é o caso, o que demandaria por sua vez uma justificação, impedindo uma interrupção fundacionista do regresso epistêmico Palavras-chave: Fundacionismo, BonJour, Dilema de Sellars, Regresso Epistêmico.
Abstract: The aim of this paper is to assess the foundationalist solution proposed by Laurence BonJour to the epistemic regress problem. According to BonJour, the non-apperceptive consciousness constitutive of the content of an occurring state of awareness would justify an apperceptive belief about that mental state. That consciousness, with respect to sensory perception, would play the role of the basic element of knowledge required by foundationalists to solve the epistemic regress problem. The assessment of this view is especially interesting because BonJour endorsed for a long time the Sellarsian criticisms of on foundationalism, but in the texts analyzed here intended to put forth a version of foundationalism that would be immune to Sellars's criticisms. In this paper I argue that BonJour's foundationalist solution does not work. Our analysis (1) assess whether BonJour's description of what is it to have entertain an occurring belief is phenomenologically adequate; (2) analyzesin what sense it is possible to compare a content with no propositional form - such as that of a sensory experience - with a propositional content of an apperceptive belief that describes it; and (3) to assesses whether the cognition of the fitness of the propositional description of a sensory content does not entail a contingent belief that this is the case, which would demand a justification, thus preventing a foundationalist halt to the epistemic regress.

Keywords: Foundationalism, BonJour, Sellar's Dilemma, Epistemic Regress.

* Doutorando do PPG-UFRGS. Email: jonatan_filosofia@yahoo.com.br.

\begin{tabular}{|c|c|l|l|c|c|}
\hline intuitio & $\begin{array}{c}\text { ISSN } \\
1983-4012\end{array}$ & Porto Alegre & Vol.8 $-\mathrm{N}^{\mathrm{o}} .2$ & $\begin{array}{c}\text { Dezembro } \\
2015\end{array}$ & p.94-113 \\
\hline
\end{tabular}




\section{A virada de BonJour}

O objetivo deste artigo é avaliar a proposta fundacionista desenvolvida por Laurence BonJour para a solução do problema do regresso epistêmico da justificação. ${ }^{1} \mathrm{O}$ problema do regresso epistêmico advém da análise padrão de conhecimento como crença verdadeira justificada. ${ }^{2}$ É um truísmo em epistemologia que, ao termos uma crença desafiada, podemos nos valer de outra crença para justificá-la. Isso porque os conteúdos proposicionais das crenças estabelecem entre si relações inferenciais e, se de uma crença se segue indutiva ou dedutivamente outra crença, aquela pode servir como razão para esta última. Esse tipo de justificação denomina-se justificação inferencial e, se nos limitamos a ele, somos levados a uma posição cética quanto à possibilidade da justificação do conjunto total de nossas crenças. Esse problema é conhecido como o "trilema de Agripa", segundo o qual, toda tentativa de justificar uma crença exige o recurso a outra crença, que por sua vez, para ser justificada, requer recurso a uma terceira crença e assim por diante, o que resultaria numa cadeia de justificação que (i) ou seguiria ad infinitum, (ii) ou seria circular por fazer recurso a uma crença que já aparecera em um momento anterior da cadeia de justificação, (iii) ou seria interrompida de maneira arbitrária. Essas três alternativas nos levam a crer que a justificação, ao fim e ao cabo, não se efetiva nunca e consequentemente, uma vez que este exige justificação, na impossibilidade do conhecimento. O fundacionismo em epistemologia defende que, para resolvermos o problema do regresso epistêmico e evitarmos uma conclusão cética, nossas crenças devem ser concebidas como consistindo em dois tipos: crenças não-básicas, que derivam sua justificação via relações inferenciais de outras crenças, e crenças básicas, que são justificadas não-inferencialmente. Para explicar a possibilidade das crenças básicas, o fundacionista tem de lançar mão do conceito de dado epistêmico, um tipo de conhecimento que possa servir como justificação para crenças, mas que por sua vez não demande ele mesmo justificação. Assim, o dado epistêmico seria o responsável por interromper o regresso epistêmico da justificação de nossas crenças, salvaguardando a possibilidade do e servindo como fundamento para o conhecimento.

Com Empirismo e filosofia da mente (1956), Wilfrid Sellars deu início a sua crítica ao que denominou "mito do dado", que se dirige à ideia de conhecimento básico e pretende denunciar a inconsistência da noção de dado epistêmico. Essa inconsistência pode ser sintetizada no que ficou conhecido como "o dilema de Sellars" e consiste no seguinte: (I) se aquilo que for designado como o elemento básico, fundacional da justificação for concebido como não tendo forma proposicional - não se

\footnotetext{
${ }^{1}$ Encontramos em BonJour (1999a, 1999b, 2001, 2006, 2008 e BonJour \&Sosa, 2003) a mesma proposta fundacionista e o mesmo modo de apresentação e defesa. Nas citações a seguir, usamos BonJour (2008), que é uma tradução para o português de BonJour (1999a); citações de outras obras de BonJour foram traduzidas por mim.

${ }^{2}$ Ver, por exemplo, Ichikawa\&Steup (2012).

${ }^{3} \mathrm{O}$ dilema não aparece formulado explicitamente na obra de Sellars, mas é sugerido por suas críticas ao fundacionismo presentes principalmente em Sellars (1956) e (1975).
}

\begin{tabular}{|c|c|c|c|c|c|}
\hline intuitio & $\begin{array}{c}\text { ISSN } \\
1983-4012\end{array}$ & Porto Alegre & Vol.8 $-\mathrm{N}^{\circ} .2$ & $\begin{array}{c}\text { Dezembro } \\
2015\end{array}$ & p.94-113 \\
\hline
\end{tabular}


assemelhando a uma crença ou asserção -, então não carecerá de justificação e será epistemicamente independente, mas não poderá justificar crenças e asserções; (II) se o elemento fundacional for concebido como tendo forma proposicional, semelhantemente a crenças e asserções, então será epistemicamente eficaz, pois em virtude de suas propriedades inferenciais pode servir como razão para o endosso de outros conteúdos proposicionais. Contudo, como qualquer conteúdo proposicional, dependerá de que outro conteúdo proposicional the dê razoabilidade, o que o torna epistemicamente dependente e, portanto, não fundacional. Se o dilema é legítimo, ele mostra que a ideia mesma de um elemento justificador que não demande justificação, o dado epistêmico, é inconsistente. Uma vez que o dado epistêmico é requerido por qualquer posição fundacionista em epistemologia, a crítica de Sellars poria o fundacionismo em bancarrota.

A crítica de Sellars ao mito do dado exerceu muita influência no debate entre fundacionistas e coerentistas. Alguns, como Rorty (1979), Brandom (1994), McDowell (1994) e BonJour (1985), tomaram por decisivo o desafio posto por Sellars ao fundacionismo. BonJour, no entanto, é um caso peculiar nesse debate, pois foi por muito tempo um ferrenho crítico do fundacionismo em epistemologia, dando seguimento a linha crítica iniciada por Sellars e sendo por muitos anos uma referência nesse sentido. Contudo, em seus trabalhos mais recentes ${ }^{4}$, rejeita a viabilidade do coerentismo como abordagem epistemológica, tachando-o de "insustentável” (2008, p. 214), e defende uma posição fundacionista internalista. ${ }^{5}$ De acordo com ele, a consciência não aperceptiva constitutiva do conteúdo de um estado consciente atual inerente a esse estado justificaria uma crença aperceptiva acerca desse estado mental ocorrente. Tal consciência não aperceptiva inerente aos estados conscientes ocorrentes, no que se refere a percepções sensoriais, cumpriria o papel de elemento básico do conhecimento que os fundacionistas exigem para a solução do problema do regresso epistêmico. Essa virada na posição de BonJour tem significância óbvia no debate iniciado por Sellars devido ao fato de BonJour conhecer a fundo e ter endossado por muito tempo a crítica sellarsiana ao fundacionismo. Ao menos somos levados a crer que ele sabe exatamente contra o que ele tem de defender o fundacionismo. Contudo, nos parece que a pretendida solução fundacionista de BonJour não alcança seu objetivo. Além de basear-se numa fenomenologia bastante controversa acerca de nossos estados conscientes, ela cai presa do mesmo dilema sellarsiano com o qual BonJour atacou o fundacionismo durante anos. No que segue (seção 2), apresentaremos a alternativa proposta por BonJour, primeiramente (2.1) no que sua concepção de consciência nãoaperceptiva constitutiva de estados conscientes se aplica a crenças ocorrentes e, na sequência (2.2), como

\footnotetext{
${ }^{4}$ BonJour (1999b), (2001) e (2008) e BonJour \&Sosa (2003).

${ }^{5} \mathrm{O}$ internalismo é uma corrente na teoria da justificação que alega que algo somente pode servir como elemento justificador para as crenças de determinado sujeito epistêmico se consistir em um estado cognitivo acessível ao sujeito em questão. A vertente opositora ao internalismo é o externalismo, que defende que algo pode cumprir o papel de elemento justificador para crenças de determinado sujeito mesmo que ele não tenha acesso cognitivo a esse elemento.
}

\begin{tabular}{|c|c|c|c|c|c|}
\hline intuitio & $\begin{array}{c}\text { ISSN } \\
1983-4012\end{array}$ & Porto Alegre & Vol.8 $-\mathrm{N}^{\circ} .2$ & $\begin{array}{c}\text { Dezembro } \\
2015\end{array}$ & p.94-113 \\
\hline
\end{tabular}


ele pretende estender essa noção às percepções sensoriais. Depois (seção 3), avaliamos a proposta de BonJour à luz de suas antigas críticas ao fundacionismo, encontradas em BonJour (1985), e sinalizamos alguns pontos que parecem problemáticos: a seção 3.1 avalia se a descrição proposta por BonJour acerca do que é entreter uma crença ocorrente possui acurácia fenomenológica; a seção 3.2 analisa em que sentido é possível a comparação entre um conteúdo sem forma proposicional, como o da experiência sensorial, e um conteúdo proposicional, da crença aperceptiva que a descreve; e a seção 3.3 avalia se a cognição da correção da descrição proposicional não implica uma crença contingente de que tal é o caso, o que demandaria por sua vez uma justificação para essa crença, impedindo a interrupção fundacionista do regresso epistêmico. Por último, na seção 4, concluímos que BonJour não parece ser capaz de responder claramente às próprias críticas que ele endossou anteriormente.

\section{A alternativa fundacionista de Bonjour}

BonJour (2008, pp. 199-200, 215) assume que a crítica que lança o mais alto desafio ao fundacionismo $^{6}$ é a posta pelo dilema de Sellars. Superar esse dilema é então uma tarefa essencial a qualquer proposta fundacionista bem sucedida em epistemologia. Tradicionalmente o fundacionismo recorreu a nossa experiência sensorial como elemento último de justificação de nossas crenças empíricas. BonJour faz o mesmo, mas para facilitar a compreensão de sua posição, primeiramente tenta mostrar como é possível que uma metacrença acerca de uma crença ocorrente esteja justificada nãoinferencialmente, para depois, por analogia, explicar como uma crença aperceptiva acerca de uma experiência sensorial pode estar justificada não-inferencialmente. Acompanhemos a argumentação de BonJour.

\subsection{Justificando uma metacrença ocorrente}

Em se tratando de uma metacrença acerca de uma crença ocorrente, quer dizer, uma crença acerca de uma crença atualmente consciente, pergunta-se BonJour, como ela poderia estar justificada nãoinferencialmente? Certamente sua justificação tem de estar de algum modo conectada com a crença ocorrente em questão. Porém ela não pode consistir em nosso conhecimento aperceptivo, isto é, nosso conhecimento acerca de nossos próprios estados conscientes, dessa crença ocorrente, pois isso corresponderia à mesma metacrença que buscamos justificar. Nem pode ela ser dependente de outras

\footnotetext{
6 Em BonJour (2008) a palavra inglesa "foundationalism" foi traduzida como fundacionalismo e assim seus derivados, contudo, por motivos de economia e estilo, preferi valer-me, no presente artigo, da tradução alternativa "fundacionismo" e seus derivados.
}

\begin{tabular}{|c|c|c|c|c|c|}
\hline intuitio & $\begin{array}{c}\text { ISSN } \\
1983-4012\end{array}$ & Porto Alegre & Vol.8 $-\mathrm{N}^{\mathrm{o}} .2$ & $\begin{array}{c}\text { Dezembro } \\
2015\end{array}$ & p.94-113 \\
\hline
\end{tabular}


crenças que possuímos, pois sua justificação seria inferencial. BonJour crê que um modo de escapar "das garras do dilema" de Sellars depende da apreciação que fazemos do que é ter consciência de uma crença ocorrente:

[...] minha percepção ou experiência mais fundamental de uma de minhas crenças ocorrentes não é nem uma crença aperceptiva ou um estado do tipo crença que, por si só, necessitasse de justificação, nem uma percepção não cognitiva de algum tipo que não reflita o caráter específico do estado apreendido, neste caso o conteúdo proposicional da crença. Sugiro, ao contrário, que, ipso facto, ter a consciência do conteúdo daquela crença (e também da aceitação que se tem daquele conteúdo), uma consciência que não é de natureza reflexiva ou aperceptiva, mas, até certo ponto, constitutiva do próprio estado de crença ocorrente de primeiro nível. (2008, p. 216).

Como vemos, segundo BonJour, ter uma crença ocorrente é ter a consciência de determinado conteúdo proposicional e da aceitação desse conteúdo. Essa consciência é qualificada em dois pontos: (1) ela não é uma consciência aperceptiva, pois se trata ainda de uma crença de primeira ordem, ela é consciência do conteúdo proposicional endossado, mas não é uma metacrença; (2) essa consciência é constitutiva da crença mesma, no sentido de que determina que a crença seja acerca do que é e não sobre outra coisa. Se fosse consciência de outro conteúdo proposicional ou de sua rejeição, seria consciência constitutiva de outra crença ocorrente.

BonJour alega que é a consciência constitutiva e não-aperceptiva da crença ocorrente de primeiro grau que justifica uma metacrença aperceptiva acerca da crença ocorrente em questão. Não somente isso, mas, em virtude das características (1) e (2), tal justificação dá-se da maneira almejada pelo fundacionista e permitiria a BonJour superar as dificuldades lançadas pelo dilema de Sellars. Em virtude de (2), já que a consciência envolvida em uma crença ocorrente é constitutiva do próprio estado de crença em questão, essa consciência é de certo modo infalível, pois ela se refere imediatamente à crença em questão e passa a existir tão pronto o estado de crença surja e, não havendo nada sobre o que ela possa estar errada, não há possibilidade lógica de erro. A característica exposta em (1) permite, segundo BonJour, que essa consciência seja cognitiva o suficiente para servir de razão para uma metacrença, pois ela é a consciência do exato conteúdo proposicional a que se refere a metacrença. Além disso, uma vez que não se trata de uma consciência aperceptiva sobre uma crença de primeira ordem, embora o conteúdo do estado de crença que ela constitui tenha forma proposicional, a consciência constitutiva desse estado de crença de primeira ordem não tem ela mesma forma proposicional e, portanto, não carece de justificação. Sintetizando a proposta de BonJour, uma análise do que é ter uma crença ocorrente mostra-nos como a consciência constitutiva, infalível e não-aperceptiva de uma crença ocorrente pode justificar uma metacrença aperceptiva sobre ela. Nesse caso, reconhece BonJour, o que faz as vezes de fundamento, de elemento basilar do conhecimento, não é a metacrença, mas a consciência constitutiva não-aperceptiva de seu

\begin{tabular}{|c|c|l|l|c|c|}
\hline intuitio & $\begin{array}{c}\text { ISSN } \\
1983-4012\end{array}$ & Porto Alegre & Vol.8 $-\mathrm{N}^{\mathrm{o} .2}$ & $\begin{array}{c}\text { Dezembro } \\
2015\end{array}$ & p.94-113 \\
\hline
\end{tabular}


respectivo estado de crença de primeira ordem (2008, p. 216). Ele também reconhece que embora a consciência constitutiva seja infalível, não se segue disso que a justificação mesma da metacrença o seja. Podem ocorrer equívocos ao correlacionarmos uma crença com sua suposta metacrença, ou por desatenção, ou por alguma anormalidade da situação. Contudo, crê BonJour, isso não impede que consideremos que em casos normais tal consciência justifica uma metacrença correspondente (2008, p. 217).

2.2 Justificando uma crença aperceptiva acerca de uma percepção sensorial

Exposta a abordagem da justificação de uma metacrença acerca de uma crença ocorrente, BonJour pretende estender o mesmo tratamento, embora reconhecendo que isso é mais complicado, à justificação de uma crença aperceptiva acerca de uma experiência sensorial. Ele acredita que, uma vez que a experiência sensorial também é um estado consciente de um sujeito, assim como uma crença ocorrente, podemos esperar encontrar em ambas uma mesma estrutura constitutiva (2008, pp. 219-20). Dando seguimento à analogia, a consciência constitutiva e não-aperceptiva do conteúdo próprio de uma experiência sensorial tem também de ser infalível e capaz de justificar uma crença aperceptiva acerca da experiência sensorial ocorrente, mas não demandar ela mesma justificação. Sendo assim, "a percepção do conteúdo sensorial também é aparentemente eficaz para exercer um papel fundamental” (2008, p. 219). Mesmo que aceitemos essa transição por analogia, deparamo-nos aqui com uma dificuldade. No caso ilustrado anteriormente, BonJour tratava de mostrar como a consciência não-aperceptiva do conteúdo proposicional de um estado de crença específico pode justificar uma respectiva metacrença. Porém, o conteúdo de nossas experiências sensoriais foi tradicionalmente concebido como sendo de natureza distinta da proposicional, seu conteúdo é fenomenal, ele tem qualidades sensíveis, não propriedades lógicas, "não é, em termos gerais ou classificatórios, uma experiência proposicional de que a experiência esteja submetida a universais ou categorias gerais" (2008, p. 219). Davidson (1986), por exemplo, alega que a "relação entre uma sensação e uma crença não pode ser lógica, uma vez que sensações não são crenças ou outras atitudes proposicionais", e, ao questionar-se sobre qual seria então esta relação, conclui “[a] resposta é, eu acho, óbvia: a relação é causal” (p. 311). Contudo, uma explicação causal do processo de formação de uma crença não mostra como ou porque a crença está justificada. BonJour concorda com essa abordagem do conteúdo da experiência sensorial e precisa por isso mostrar como a consciência nãoaperceptiva de algo não proposicional, o conteúdo fenomenal da percepção sensorial, poderia justificar o endosso de um conteúdo proposicional, a crença aperceptiva acerca dessa experiência. Se a relação não pode ser lógica e uma relação causal é inepta, qual é a relação entre o conteúdo fenomenal e o conteúdo proposicional que faz com que a consciência do primeiro justifique o segundo? A resposta de BonJour

\begin{tabular}{|c|c|c|c|c|c|}
\hline intuitio & $\begin{array}{c}\text { ISSN } \\
1983-4012\end{array}$ & Porto Alegre & Vol.8 $-\mathrm{N}^{\circ} .2$ & $\begin{array}{c}\text { Dezembro } \\
2015\end{array}$ & p.94-113 \\
\hline
\end{tabular}


(2008, p. 220) é que a relação em questão é descritiva. Somos conscientes do conteúdo fenomenal de nossas percepções sensoriais e, uma vez que tenho capacidades conceituais suficientes, sou capaz, em tese, de descrever de maneira proposicional corretamente o conteúdo não-proposicional da minha percepção sensorial, e de constatar a correção dessa descrição. Para ele, não há razão para negar que isso seja possível, de fato isso consistiria em um procedimento em si mesmo simples e corriqueiro, e ninguém estaria em melhores condições de avaliar se determinada descrição corresponde a determinado conteúdo sensorial do que a própria pessoa que tem a experiência (p. 220).

Vejamos um exemplo: de acordo com a proposta de BonJour, se um sujeito está diante de vários balões coloridos e por algum motivo lhe é suscitada uma dúvida acerca da presença de um balão vermelho, esse sujeito, ao compreender o que algo precisa ser para ser um balão vermelho, é capaz de identificar em sua experiência um elemento que se encaixe nessa descrição. Ele passaria então a sustentar a crença de que há um balão vermelho diante dele e tal crença seria justificada precisamente pela "consciência do ajuste descritivo entre o conteúdo da proposição [acreditada] e o aspecto relevante do conteúdo da experiência (BonJour, 2006, p 744). Se essa for a compreensão correta da relação entre nossa percepção sensorial e a crença que a descreve, BonJour assume que nesses casos de justificação de uma crença aperceptiva acerca de uma experiência sensorial nos deparamos com uma confrontação entre "uma descrição conceitual e um bloco não-conceitual da realidade que ela pretende descrever, e que muitos filósofos, infelizmente incluindo eu mesmo ${ }^{7}$, rejeitaram e classificaram como impossível” (2008, p. 221). Ele reconhece que, no tocante a essa confrontação, ela somente ocorre na medida em que "a realidade em questão seja um estado consciente". Nesse "caso muito específico ela [a confrontação] parece ser inteiramente simples". Sendo assim, seria possível que uma experiência sensorial, não-proposicional, justificasse uma crença aperceptiva sobre ela. BonJour conclui "que o dado não é, afinal de contas, um mito" (2008, p. 221) e que esteve errado sobre isso anteriormente. Ele antevê certas dificuldades para sua posição $^{8}$ e ensaia em linhas gerais algumas soluções possíveis para elas. Contudo, no tocante aos interesses do presente trabalho, convém apenas destacar que BonJour crê ser capaz de superar o dilema de Sellars e que o fundacionismo, com respeito ao seu primeiro e mais difícil desafio, estaria a salvo. No que se segue, avaliamos a viabilidade e a plausibilidade da proposta de BonJour à luz das críticas que ele mesmo, em seu tempo de coerentista, dirigia ao fundacionismo, e se ela realmente alcança seus objetivos.

\footnotetext{
${ }^{7}$ Ver principalmente BonJour (1985, cap. 4).

${ }^{8}$ BonJour reconhece que sua proposta fundacionista precisa explicar qual a eficácia de tais crenças aperceptivas em nossa economia epistêmica, qual maneira correta de conceitualizar os conteúdos sensoriais da percepção e, como corolário, se após termos estabelecido como fundamento para o conhecimento empírico nossas crenças aperceptivas acerca de nossos estados subjetivos, é possível resgatarmos nossa crença em um mundo objetivo independente de nós? Não avaliaremos aqui estas questões. Detemo-nos apenas na viabilidade da proposta mesma de BonJour, e não em suas consequências.
}

\begin{tabular}{|c|c|c|c|c|c|}
\hline intuitio & $\begin{array}{c}\text { ISSN } \\
1983-4012\end{array}$ & Porto Alegre & Vol.8 $-\mathrm{N}^{\mathrm{o}} .2$ & $\begin{array}{c}\text { Dezembro } \\
2015\end{array}$ & p.94-113 \\
\hline
\end{tabular}




\section{Problemas para a concepção de BonJour}

Nossa análise da proposta de BonJour terá como pano de fundo suas próprias críticas ao fundacionismo, que remontam a sua fase inicial de coerentista, e se deterá em três pontos: (3.1) se a descrição proposta por BonJour acerca do que é entreter uma crença ocorrente possui acurácia fenomenológica; (3.2) em que sentido é possível a comparação entre um conteúdo sem forma proposicional, como o da experiência sensorial, e o conteúdo proposicional da crença aperceptiva que o descreve; e (3.3), se tal comparação for possível, se a cognição da correção da descrição proposicional não consiste na crença contingente de que tal é o caso, o que demandaria por sua vez uma justificação para essa crença, impedindo a parada do regresso epistêmico.

\section{$3.1 \mathrm{O}$ olho da consciência}

Comecemos com a avaliação da noção mesma de "consciência não-aperceptiva constituinte de estados conscientes ocorrentes" proposta por BonJour e que está na base de sua concepção fundacionista internalista do conhecimento. Essa consciência constitutiva é introduzida por ele ao examinar um caso de crença ocorrente 9 . Segundo BonJour (2008, p. 216), "ter uma crença ocorrente é, ipso facto, ter a consciência do conteúdo daquela crença (e também da aceitação que se tem daquele conteúdo)”. Como já sabemos, tal consciência não pode ser compreendida como uma consciência aperceptiva, posto que já seria uma consciência de segunda ordem, mas será que essa é uma boa descrição dos nossos estados conscientes?

Diz-se que o característico da consciência é a sua intencionalidade, a propriedade que ela tem de sempre se direcionar a algo, de ser acerca de algo enquanto algo. Façamos uma análise do que é, do ponto de vista fenomenológico, entreter uma crença ocorrente e busquemos a alegada "consciência constitutiva" defendida por BonJour. Quando vejo um gato preto e tenho a crença de que o gato é preto, o objeto para o qual minha consciência está dirigida é o gato, que por sua vez é tomado como sendo preto. Nisso consiste a consciência de uma crença de primeira ordem, seu objeto é o gato e o como o gato aparece é como sendo gato e preto. Embora acreditar que o gato seja preto e endossar ou tomar por verdadeiro o conteúdo proposicional "o gato é preto" possam ser equiparados de um ponto de vista da estrutura lógica do que é ter uma crença ocorrente, elas não são a mesma coisa do ponto de vista da experiência fenomenológica de primeira pessoa. Isso porque, no primeiro caso, o objeto ao qual a consciência se dirige é o gato, e o toma

\footnotetext{
9 Abordaremos na próxima seção a proposta de BonJour de que a experiência fenomênica é um estado mental consciente não conceitual, sem forma proposicional, nos limitando no momento a abordar sua concepção de crença ocorrente como estado mental consciente..
}

\begin{tabular}{|c|c|c|c|c|c|}
\hline intuitio & $\begin{array}{c}\text { ISSN } \\
1983-4012\end{array}$ & Porto Alegre & Vol.8 $-\mathrm{N}^{\mathrm{o}} .2$ & $\begin{array}{c}\text { Dezembro } \\
2015\end{array}$ & p.94-113 \\
\hline
\end{tabular}


como sendo preto, mas no segundo caso, a consciência se dirige a um conteúdo proposicional como um todo e o toma como sendo verdadeiro, o aceita ou endossa. De uma perspectiva de primeira pessoa, não poderíamos endossar conscientemente um conteúdo proposicional sem que tal consciência consistisse em uma consciência de segunda ordem. BonJour defende que essa consciência seria constitutiva da própria crença de primeira ordem e da experiência fenomênica, tornando-os estados conscientes por si mesmos, independentemente de outros estados conscientes, e assim evitando os problemas oriundos de concepções de estados conscientes como a de Rosenthal (1986). BonJour alega que , para Rosenthal,

[...] a consciência não é uma propriedade intrínseca de qualquer estado mental. Ao contrário, um estado mental torna-se consciente somente por ser o objeto de um segundo estado mental, um "pensamento de ordem maior" de que se tem ou está no primeiro estado mental (BonJour \& Sosa, 2003, p. 66).

O problema com a concepção de Rosenthal é que, para que um estado mental seja consciente, ele deve ser objeto de um metaestado mental, que, por sua vez, somente será um estado mental consciente se for objeto de um meta-metaestado mental e assim sucessivamente, o que gera um regresso infinito e atesta a impossibilidade de tal concepção de estados mentais conscientes. Podemos entender a posição de BonJour como uma alternativa à concepções como a de Rosenthal, porém isso não a torna mais clara. .Voltando ao exemplo acima, caso eu seja questionado acerca de minha crença sobre o gato preto, o que estará em questão é se o gato tem a propriedade ou não de ser preto, ou se o que eu tomo por gato é mesmo um gato. Já num caso em que aceito ou não um conteúdo, minha consciência direciona-se a algo mais complexo, “creio que 'o gato é preto"” ou “"o gato é preto' é correto”. Nesse caso, o que está em questão é se o conteúdo "o gato é preto" tem ou não a propriedade de ser verdadeiro, se é correto, se devo aceitá-lo ou não, e isso é sem dúvida uma questão de segunda ordem. Embora uma boa definição do que é acreditar que $x$ tem a propriedade $F$ é “endossar o conteúdo proposicional que $p$ ”, de um ponto de vista de primeira pessoa, devido a natureza de contextos intensionais, acreditar que certo objeto possui certa propriedade não é a mesma coisa que acreditar que certo conteúdo proposicional é verdadeiro. Essa é uma dificuldade que se apresenta às tentativas de se realizar uma análise fenomenológica de nossos estados conscientes, porque ao nos debruçarmos sobre eles para descrevê-los, acabamos por descaracterizá-los. Numa consciência de primeira ordem, os conteúdos dos quais em geral temos consciência são objetos e suas propriedades, mas não temos consciência de conteúdos qua conteúdos que são aceitos ou rejeitados, isso já corresponde uma consciência de segunda ordem, posto que já os tomamos qua conteúdos de consciência.

Não fica exatamente claro a que BonJour se refere com o conceito de "consciência constitutiva"; ela não é algo, uma coisa, diferente do conteúdo da consciência, mas é o que torna tais conteúdos cognitivamente disponíveis para nós. Porém é difícil não pensar que, ao falarmos que uma crença

\begin{tabular}{|c|c|l|l|c|c|}
\hline intuitio & $\begin{array}{c}\text { ISSN } \\
1983-4012\end{array}$ & Porto Alegre & Vol.8 $-\mathrm{N}^{\mathrm{o} .2}$ & $\begin{array}{c}\text { Dezembro } \\
2015\end{array}$ & p.94-113 \\
\hline
\end{tabular}


ocorrente exige algo que seja constitutivo de seu conteúdo, mas que ao mesmo tempo não é seu conteúdo e não é algo diferente desse estado de consciência, sem recairmos na velha ideia do "olho da consciência" muito criticada anteriormente por BonJour. No caso da consciência de conteúdos perceptivos, se vejo que o gato é preto, pressupõe-se que haja um conteúdo sensorial preto em minha experiência, mas tenho consciência do gato como sendo preto e não de minha experiência como sendo de um conteúdo sensorial preto. Se passo a refletir sobre o preto em minha experiência, tenho uma atenção aperceptiva acerca de um conteúdo de minha consciência, não mais sobre o gato, e isso é então, por definição, uma consciência de segunda ordem. O BonJour fundacionista parece valer-se de uma concepção acerca da consciência como um "olho" que vê tudo que passa no palco de nosso teatro mental e, sendo espectadora dos conteúdos que perante ela se apresentam, está apta a discriminá-los e compará-los quando bem entender. Tal posição fora anteriormente rejeitada por ele:

A sugestão é que consciência imediata é simplesmente a forma mais básica de confrontação entre a mente ou a consciência e seus objetos, a situação na qual o objeto está diretamente aberto para o olhar do olho mental. E se essa metáfora fosse para ser levada a sério, a confrontação poderia justificar uma crença enquanto negando que qualquer questão significativa acerca da justificação do ato mesmo possa surgir. Mas parece relativamente claro que a metáfora do olho mental não suportará tanto peso. (BonJour, 1985, p. 79)

BonJour (2008) recorre a essa abordagem do que é estar consciente de algo para que a alegada "consciência não-aperceptiva constitutiva" sirva como elemento justificador básico de crenças apercetivas. Porém, ao menos não é muito claro que ela, se de fato ocorre, possa desempenhar o papel para o qual é requisitada. Como afirmava BonJour (1985), esse tipo de apelo a estados mentais parece ajudar em certa medida "somente por causa da grave obscuridade ligada à concepção mesma de tais estados" (p. 78). O atual BonJour não convenceria o antigo com essa concepção de consciência não-aperceptiva constitutiva, mas sigamos com a avaliação.

\subsection{Comparando o incomparável?}

Concedamos a BonJour que de fato há uma consciência não-aperceptiva constitutiva de uma percepção sensorial. Para que ela possa desempenhar seu papel de elemento justificador de uma crença aperceptiva sobre a experiência ocorrente, tem de ser possível a comparação entre um conteúdo nãoproposicional com um conteúdo proposicional. Vejamos que sentido podemos dar para uma comparação desse gênero.

Digamos que eu olhe na direção de um gato preto e perceba que o gato é preto, e forme assim a crença de que pareço estar vendo um gato preto ou que me parece que o gato é preto. De acordo com BonJour, o conteúdo entre aspas, "me parece que o gato é preto", seria a minha crença aperceptiva acerca

\begin{tabular}{|c|c|c|c|c|c|}
\hline intuitio & $\begin{array}{c}\text { ISSN } \\
1983-4012\end{array}$ & Porto Alegre & Vol.8 $-\mathrm{N}^{\circ} .2$ & $\begin{array}{c}\text { Dezembro } \\
2015\end{array}$ & p.94-113 \\
\hline
\end{tabular}


do conteúdo da minha percepção visual do gato preto. Além do conteúdo proposicional da crença aperceptiva, estaria em jogo o conteúdo sensorial da experiência mesma, que, como BonJour alega, não seria proposicional, nem conceitual, não estaria categorizado nem classificado. A consciência nãoaperceptiva constitutiva do conteúdo não-proposicional da minha experiência permite, segundo BonJour, que se compare o conteúdo sensorial com o conteúdo proposicional que o descreve, constatando a correção ou não desta descrição. As perguntas que surgem são: como se dá essa comparação, que critério temos para sua correção? No caso de comparar o conteúdo de uma metacrença aperceptiva com o conteúdo de uma crença ocorrente, não há um problema de falta de critério, pois ambas possuem conteúdo proposicional similar. É devido a essa facilidade de comparação entre conteúdos proposicionais que BonJour inicia sua análise acerca da justificação de uma metacrença e somente depois, por analogia, estende essa análise ao caso mais problemático da experiência sensorial. No exemplo acima, eu, segundo BonJour, posto que possuo as capacidades conceituais necessárias e compreendo como minha experiência deveria ser para que minha crença seja verdadeira, estaria em condições de comparar o conteúdo da minha crença aperceptiva de que me parece que o gato é preto, com o conteúdo mesmo da experiência sensorial, não conceitual, verificando seu ajuste. Porém, qual é esse conteúdo sensorial? É difícil encontrar em nossa experiência, no que toca aos seus aspectos cognitivos, essa duplicidade de conteúdos; simplesmente parece-nos que o gato é preto e esse é o conteúdo cognitivo da nossa experiência, não é evidente que haja algo que seja, ao mesmo tempo, inteligível em nossa experiência, mas que seja independente de uma compreensão conceitualizada. Quer dizer, é claro que há uma diferença qualitativa entre pensar em um gato preto e ver um gato preto, mas esse plus sensorial que existe num caso de percepção parece fazer-se cognitivamente disponível somente na media em que é conceitualizado como sendo assim e assado. Nossas experiências sensoriais, se inteligíveis, nos apresentam as coisas como sendo assim e assado, de certo tipo, em certa relação, ou seja, em uma articulação semelhante à articulação proposicional. Não precisamos, normalmente, interpretar, fazer inferências ou construir nossa experiência a partir de dados sensoriais, conteúdos fenomenais não organizados conceitualmente. Em geral já experienciamos as coisas de modo inteligível, como uma bola te futebol suja, uma jarra de suco de uva ao lado de um sanduíche, o Gabriel como sendo mais baixo que o Bruno, um gato preto dormindo etc. Nossa experiência nos apresenta certos arranjos de algo enquanto algo, certos estados de coisas que podem ser tomados por seu valor de face ou rejeitados como ilusórios. Porém o conteúdo da experiência é tão cognoscível, passível de ser acreditado, de ser verdadeiro, de servir como razão para outras crenças, e por isso mesmo demandar razões para nossos posicionamentos para com ele - se o endossamos ou não -, que não parece ser menos articulado conceitualmente que outros conteúdos proposicionais. Como eu poderia descrever minha experiência de que percebo um gato preto se ela mesma já não fosse estruturada, determinada de certa maneira, como me apresentado o gato como sendo preto? Se o conteúdo de nossa experiência sensorial

\begin{tabular}{|c|c|c|c|c|c|}
\hline intuitio & $\begin{array}{c}\text { ISSN } \\
1983-4012\end{array}$ & Porto Alegre & Vol.8 $-\mathrm{N}^{\circ} .2$ & $\begin{array}{c}\text { Dezembro } \\
2015\end{array}$ & p.94-113 \\
\hline
\end{tabular}


fosse um mero bloco sensorial não organizado conceitualmente em forma proposicional, como poderíamos decidir entre duas ou mais descrições concorrentes? A percepção de um gato preto é incompatível com a descrição do mesmo em termos de uma bola de futebol furada, ou de um gato branco, ou de um cão preto. Mas isso parece ser o caso porque a experiência sensorial já nos apresenta algo organizado em forma proposicional como $a$ é $F$, o gato é preto.

Isso tudo não significa negar que haja um conteúdo sensorial, fenomenal em nossas experiências sensoriais. Sellars, por exemplo, argumenta que tal conteúdo fenomenal é necessário, mas não suficiente para que nossa experiência seja algo cognitivo. A ideia de que, se tenho uma experiência sensorial de certo tipo, estou em condições de saber que ela é desse certo tipo tem bastante apelo intuitivo. Porém ela constitui justamente o âmago da ideia de apelo a um dado epistêmico que foi criticada por Sellars. ${ }^{10}$ Além do conteúdo fenomenal, ela tem de apresentar um caráter intencional, ser acerca de algo enquanto algo, ou seja, ter uma estrutura proposicional para daí sim poder ser uma experiência cognitiva acerca de algo enquanto algo, para mostrar-nos que algo é o caso. Sem tal articulação conceitual, a percepção sensorial seria cognitivamente inócua, inerte. Não se trata, porém, de alegar que precisamos interpretar o conteúdo fenomenal de nossa percepção e posteriormente anexar a ele um conteúdo proposicional, essa ideia é justamente uma das faces do mito. Ambos os conteúdos já se apresentam simultaneamente em nossa experiência, fazendo dela o ato cognitivo específico que é. Esse duplo aspecto da experiência sensorial foi, segundo Sellars (2005, pp. 30-1), muitas vezes confundido e tomado como uma e mesma face de nossa experiência sensorial. Coates (2007) desenvolveu recentemente, sob a luz da atual ciência cognitiva, a abordagem sellarsiana acerca de nossas experiências sensoriais, denominada "realismo crítico". De acordo com o realismo crítico, "estar consciente de algo é estar consciente de que tipo (kind) ele é [...] Consciência não é o simples registrar de itens fenomenais na experiência; ela essencialmente envolve classificação" (Coates, 2007, p 43). Sendo assim, o "conteúdo fenomenal somente pode ser discriminado pelo exercício de conceitos de algum tipo (Coates, 2007, p 44). BonJour (1999b, 2001, 2003 e 2008) defende que a consciência constitutiva do conteúdo descritivo de nossa percepção permitiria a comparação deste com uma descrição proposicional do mesmo. A comparação dar-se-ia em termos do ajuste da experiência fenomênica não-conceitual para com sua descrição conceitual, proposicional. (BonJour \& Sosa, p.72) Porém, é difícil ver como algo sem articulação conceitual em nossa experiência poderia ser cognitivamente acessado de maneira que possibilitasse a alegada comparação, sem que tal cognição não

\footnotetext{
${ }^{10}$ Em uma obra tardia, na qual avalia a trajetória de sua crítica ao mito do dado, Sellars explicita que a formulação mais básica da concepção que ele pretende denunciar como sendo mítica é a ideia de que "[s]e uma pessoa está diretamente consciente de um item que tem status categorial C, então essa pessoa está consciente disso como tendo o status categorial C" (1981, p. 11). O ponto aqui é rejeitar a ideia empirista tradicional de que ter uma percepção sensorial implica em um estado cognitivo acerca dessa percepção que independe de qualquer outro conhecimento que possamos ter. Para Sellars, a presença desse estado cognitivo pressupõe um background de habilidades conceituais e outros conhecimentos incompatíveis com a abordagem atomista do empirismo tradicional.
}

\begin{tabular}{|c|c|l|l|c|c|}
\hline intuitio & $\begin{array}{c}\text { ISSN } \\
1983-4012\end{array}$ & Porto Alegre & Vol.8 $-\mathrm{N}^{\circ} .2$ & $\begin{array}{c}\text { Dezembro } \\
2015\end{array}$ & p.94-113 \\
\hline
\end{tabular}


fosse ela mesma articulada de forma proposicional. Em um texto de sua época coerentista, BonJour (1985, p. 64) discute a proposta de Schlick (1934-35) de que seria possível comparar o enunciado "Essa catedral possui duas torres" com a própria catedral e decidir se corresponde ou não aos fatos. O enunciado é proposicional em sua forma, a catedral, não. Schlick sustenta que podemos comparar um conteúdo descritivo de uma proposição com aquilo que ele descreve para determinar sua correção. BonJour aceita que corriqueiramente comparamos um objeto a outro, contudo "é óbvio que de um ponto de vista epistemológico, nós fazemos isso somente por de algum modo perceber ou apreender ou experienciar esses objetos" (1985, p. 64). A questão reside no fato de como devemos entender tais apreensões e experiências. BonJour (1985), nesse ponto, concorda com a resposta de Hempel a Schilick, segundo a qual a apreensão da catedral, a fim de "verificar" a descrição, consistiria no enumerar suas torres, o que resultaria no conteúdo proposicional "Eu agora vejo duas torres" ou algo que o valha (BonJour, 1985, p. 64). A conclusão de BonJour é que a ideia de apelo a uma comparação entre conteúdos proposicionais e não-proposicionais "colapsa". Pois, para resolver o problema do regresso epistêmico por recurso a essa comparação, tem de ser "possível construir a experiência imediata ou a apreensão direta" do conteúdo dado "de maneira que não envolva um julgamento ulterior ou aceitação proposicional”, para não se gerar uma nova demanda por justificação (1985, pp. 64-5).

Como vimos até aqui, a alegação de BonJour (2008) de que há uma comparação entre o conteúdo proposicional de uma crença descritiva acerca de uma percepção sensorial ocorrente e do conteúdo nãoproposicional sensorial dessa percepção parece ser possível somente na medida em que o conteúdo sensorial é apreendido de determinada maneira, como sendo de tal e tal modo. A classificação do conteúdo fenomênico apreendido em uma experiência sensorial consciente como sendo de tal e tal modo se dá através de sua descrição e seria possível para o sujeito da experiência verificar a correção desta descrição. Contudo, essa apreensão fenomênica parece consistir ela mesma já em um conteúdo proposicional, na verdade, o próprio conteúdo expresso pela crença descritiva que se pretende justificar. Assim sendo, a alegada comparação entre o conteúdo conceitual e bloco não-conceitual da realidade parece não se dar exatamente da maneira pretendida por BonJour. Também não é claro de que maneira ela poderia auxiliar a superar o dilema de Sellars, se o conteúdo sensorial somente se torna cognitivo na medida em que é apreendido proposicionalmente, tal apreensão, apesar de poder servir como razão para crenças, demandaria ela mesma uma razão para sua aceitação.

3.3 O dilema sai pela porta da frente para entrar pela porta de trás

Digamos agora, porém, que a comparação entre esses dois conteúdos, proposicional e sensorial, seja possível da maneira como almeja BonJour. Vejamos se isso é suficiente para que ele escape às garras

\begin{tabular}{|c|c|c|c|c|c|}
\hline intuitio & $\begin{array}{c}\text { ISSN } \\
1983-4012\end{array}$ & Porto Alegre & Vol.8 $-\mathrm{N}^{\circ} .2$ & $\begin{array}{c}\text { Dezembro } \\
2015\end{array}$ & p.94-113 \\
\hline
\end{tabular}


do dilema de Sellars. Bergman (2006) acha que não e acusa BonJour de cair presa do dilema de Sellars em suas duas opções, alternadamente. Quando sob ameaça de que a consciência constitutiva do conteúdo sensorial seja entendida como tendo forma similar à de um juízo ou crença, o que criaria a demanda por justificação, BonJour alega que ela é não conceitual, não articulada de maneira proposicional, enfim, não é nenhum tipo de juízo. Nesse momento, ele cai presa da parte do dilema que alega que a mera consciência de algo sem forma proposicional apesar de não precisar de justificação, não pode servir como justificação de crenças. Para solucionar esse problema, BonJour tem de defender que o sujeito que tem uma experiência perceptual está em condições de comparar o conteúdo fenomenal de sua experiência com o conteúdo proposicional que a descreve e "pensar se a descrição conceitual é ou não é exata na medida em que acontece - e, se ela aparenta ser exata, se aparenta ser justificada naquela base ao aceitar a crença" (BonJour, 2008, p.220). Para que a crença aperceptiva esteja justificada, de acordo com a posição de BonJour, não basta que a descrição que ela faz esteja correta. Pois, em virtude de sua posição internalista, a correção da descrição tem de estar disponível ao sujeito epistêmico, ela tem de ser apreendida de alguma forma para que possa servir de razão para a crença em questão. Essa apreensão parece somente poder ser concebida como consistindo na crença ou juízo de que a descrição é correta, e isso é claramente uma crença contingente que demanda justificação como qualquer outra. Assim, podemos ver que, ao tentar defender-se da parte do dilema de Sellars que alega a ineficácia epistêmica de conteúdos nãoproposicionais, BonJour é vítima da parte que alega a dependência epistêmica de conteúdos com forma proposicional. Encontramos em BonJour (2003) uma tentativa de invalidar a ideia de que a apreensão da correção da descrição do conteúdo fenomenal de uma experiência sensorial implicaria um novo juízo. Para BonJour, defender que

[...] uma comparação direta entre dois estados conscientes precisa envolver um julgamento independente que por sua vez precisa ser justificado por outra coisa que os conteúdos mesmos dos estados conscientes [é] um caso claro de objetável sobreintelectualização. Se alguma comparação ou avaliação intelectual pode porventura ser direta e não mediada por um juízo adicional, certamente essa [a consciência constitutiva] pode. E negar que isso seja mesmo possível é garantir regresso vicioso em todas as direções, tornando a operação do intelecto inerentemente fútil. (2003, p. 65)

Contudo, é difícil concordar com BonJour e aceitar que a apreensão da comparação não tem a forma proposicional de um juízo acerca da correção da descrição. Como argumenta Bergman (2006, p. 687), se a posição internalista da justificação exige que o sujeito tenha acesso cognitivo ao fato de que sua percepção sensorial é de certo tipo, que poderia ser corretamente descrito por uma crença $p$, ela não pode negar que esse reconhecimento tem a forma proposicional de um juízo, uma crença. Assim, a "sobreintelectualização" deve ser atribuída à própria concepção internalista da justificação que,

\begin{tabular}{|c|c|c|c|c|c|}
\hline intuitio & $\begin{array}{c}\text { ISSN } \\
1983-4012\end{array}$ & Porto Alegre & Vol.8 $-\mathrm{N}^{\circ} .2$ & $\begin{array}{c}\text { Dezembro } \\
2015\end{array}$ & p.94-113 \\
\hline
\end{tabular}


diferentemente das posições externalistas, exige que o sujeito epistêmico tenha acesso aos elementos justificadores de suas crenças.

BonJour (2006), em suas réplicas a comentadores, reconhece que em seu livro (BonJour \& Sosa, 2003), que é objeto da crítica de Bergman acima, ao apresentar sua proposta, limitou-se apenas a sugerir algo que é "intuitivamente óbvio". Ele não crê que seja duplamente vítima do dilema de Sellars, como afirma Bergman, e em sua defesa trata de explicitar melhor os elementos componentes da suposta justificação não-inferencial, vejamos. Primeiramente, (A) a alegação proposicional de que a experiência é de certo modo é claramente conceitual e pode vir a tornar-se uma crença, e como tal, precisa ser justificada de algum modo. Já (B) a "consciência mais básica do elemento experiencial” é em si mesmo "não-conceitual e não-proposicional, não envolvendo nenhum tipo de crença ou julgamento ou qualquer coisa que precisaria ou mesmo admitiria justificação" (BonJour, 2006, p. 744). Claro está, reconhece BonJour, que a mera presença desses dois elementos na consciência, de acordo com o dilema de Sellars e a exigência internalista que ele aceita, é insuficiente para que tenhamos uma crença básica justificada nãoinferencialmente. Pois (B), em si mesmo, é epistemicamente inerte, devido a sua falta de articulação proposicional, e (A), embora apresente conteúdo proposicional, carece de justificação. O que é requerido, além de (A) e (B), é que (C) "eu reconheça ou apreenda o ajuste ou a concordância dos dois tipos de conteúdos" (BonJour, 2006, p. 744). O ponto (C) é denunciado por Bergman como implicando uma espécie de julgamento que por sua vez careceria de justificação, dando continuidade ao regresso epistêmico. Mas BonJour crê que essa alegação é infundada e que Bergman não nos oferece nenhuma argumentação para sustentá-la, "Por que supor que deveria ser assim?”, pergunta-se BonJour (2006, p. 745).

A posição de Bergman, segue BonJour, deve basear-se na ideia de que a consciência dos elementos (A) e (B) é apenas capaz de causar, de suscitar o "reconhecimento"da correção do ajuste dos conteúdos sensorial e doxástico, o que para Bergman não poderia ser outra coisa senão uma crena acerca dessa correção. Contudo, tais conteúdos não desempenhariam nenhum papel epistêmico em relação a essa crença, pois ela teria de recorrer a outras crenças para estar justificada. BonJour reconhece que tal ideia também estava presente em suas antigas críticas ao fundacionismo, baseadas no dilema de Sellars, mas que agora ela lhe parece "clara e obviamente errada" (2006, p. 745).

Certamente, no exemplo imaginado, não preciso de algum tipo de justificação adicional, independente, para pensar que a alegação proposicional se ajusta à minha experiência e por isso é verdadeira. Ao contrário, minha justificação brota da minha consciência do conteúdo da alegação e da correspondente experiência. Com certeza, tenho que reconhecer o ajuste entre os dois, mas esse reconhecimento não é um julgamento adicional cognitivamente independente, que então exigiria justificação adicional independente, mas, em vez disso, é guiado cognitivamente por e baseado nessas próprias experiências. Em um nível intuitivo, esse ponto parece a mim inteiramente óbvio. (2006, pp. 745-6)

\begin{tabular}{|c|c|l|l|c|c|}
\hline intuitio & $\begin{array}{c}\text { ISSN } \\
1983-4012\end{array}$ & Porto Alegre & Vol.8 $-\mathrm{N}^{\mathrm{o} .2}$ & $\begin{array}{c}\text { Dezembro } \\
2015\end{array}$ & p.94-113 \\
\hline
\end{tabular}


BonJour tenta deixar sua posição ainda mais clara com outro exemplo: pensemos em alguém que é mandado a uma sala para ver se há pessoas na mesma e tenha de relatar isso pelo celular. Segundo ele, essa pessoa entra na sala e simplesmente compara o conteúdo proposicional "há $x$ pessoas na sala" com o estado de coisas não-proposicional que ele encontra na sala em questão e reconhece a correção ou a falta de correção da descrição. BonJour não utiliza o termo "comparação", mas sim o "reconhecimento do acordo ou desacordo" entre a proposição descritiva e a experiência do estado de coisas descrito, e alega que "esse reconhecimento é justificado pelo ajuste de sua experiência do estado de coisas e seu entendimento da proposição relevante e não de uma maneira adicional independente" (2006, p. 746). No entanto é difícil não ligar a ideia de um reconhecimento de acordo ou desacordo entre dois estados mentais com a comparação dos mesmos. E, como vimos acima, no caso de Schlick e as torres da catedral, o antigo BonJour (1985) negava que tal comparação fosse possível, pois esses casos de comparação dão-se entre um conteúdo proposicional e nossa apreensão de um estado de coisas, e essa apreensão precisa ser articulada de maneira proposicional para que seja cognitiva. Contudo, para o BonJour fundacionista, exigir que o sujeito do exemplo acima tenha de justificar a sua crença sobre a correção de sua crença descritiva, sem que algo no contexto ponha tal crença em dúvida, não passaria de algo "obviamente bobo" (2006, p. 746). Deveríamos entender o reconhecimento do ajuste entre (A) e (B) como um ato cognitivo distinto, (C), mas não como se fosse de certa forma epistemicamente independente da consciência de (A) e (B), e que necessitasse do recurso a elementos cognitivos adicionais para estar justificado, o que sugere Bergman. $\mathrm{O}$ ato cognitivo (C), alega BonJour, não pode ser identificado com a aceitação de um conteúdo proposicional, mas também não o podemos conceber como completamente não-conceitual, pois envolve em um de seus elementos o conteúdo proposicional da crença descritiva, (B). Ele afirma então:

[...] aparentemente estou apto, dentro de um e mesmo ato cognitivo, a compreender o conteúdo da proposição e a situação não-proposicional (embora parcialmente conceitual) que o torna verdadeiro, e ver direta e imediatamente que as condições de verdade para a proposição estão satisfeitas. O resultado é de fato um julgamento proposicional, mas um cuja justificação já está presente no ato cognitivo donde ele surge. (2006, p. 747)

BonJour reconhece que Bergman ou alguém com ideias parecidas poderia pensar que tal estado cognitivo, misto de conteúdo proposicional, sensorial e seu ajuste,(C), que resulta num juízo mas não é ainda um juízo, não é possível. Pois somente o que possui a forma proposicional de um juízo é um estado cognitivo legítimo, que tanto pode servir como precisar de justificação. Para BonJour, essa compreensão acerca de estados mentais, embora recorrente em filosofia, "é falsa, baseada em uma taxonomia crua acerca de estados mentais" (2006, p. 747). Ele, porém, não nos oferece aqui nenhuma argumentação a favor da sua concepção acerca de estados mentais, mas apenas afirma o oposto:

\begin{tabular}{|c|c|c|c|c|c|}
\hline intuitio & $\begin{array}{c}\text { ISSN } \\
1983-4012\end{array}$ & Porto Alegre & Vol.8 $-\mathrm{N}^{\circ} .2$ & $\begin{array}{c}\text { Dezembro } \\
2015\end{array}$ & p.94-113 \\
\hline
\end{tabular}


[...] que uma consciência direta do ajuste de fato ocorra no tipo de caso em questão de um modo que produza justificação parece-me muito mais óbvio que qualquer concepção geral acerca de quais tipos de estados mentais são possíveis possa esperar ser. (2006, pp. 747-8)

A alegação da pretensa obviedade da concepção de um estado consciente que consistiria na apreensão do ajuste entre crença e conteúdo fenomenal não auxilia em nada, nesse caso, na tarefa de mostrar indícios acerca de sua efetividade. Em sua época de crítico do fundacionismo em epistemologia, BonJour (1985) rejeitava o recurso a tais tipos de estados mentais "semi-cognitivos", nem completamente conceituais, nem completamente não-conceituais. Para ele, àquela época, a concepção de tal estado era "irremediavelmente artificial e ad hoc" (1985, p. 77) e visava a somente superar as dificuldades do regresso epistêmico. BonJour (1985, p. 77) diz que se esse tipo de solução fosse aceito, poderíamos então pôr fim a qualquer problema de regresso, simplesmente

[...] postulando um termo final no regresso que é suficientemente familiar ao termo prévio para satisfazer, com respeito ao penúltimo termo, o tipo de necessidade ou ímpeto que originariamente gerou o regresso; mas que é suficientemente diferente do termo prévio para que ele mesmo não exija tal satisfação por ainda outro termo adicional. Então poderíamos ter semi-eventos, que poderiam causar, mas não precisam ser causados; semi-explanantia, que poderiam explicar, mas não precisariam ser explicados e semi-crenças, que poderiam justificar, mas não precisariam ser justificadas. O ponto não é que tais medidas são sempre incorretas (embora eu suspeite que sejam), mas meramente que a natureza e possibilidade de tais termos intermediários convenientes precisam ao menos ser clara e convincentemente estabelecidas antes que possam constituir uma solução satisfatória para qualquer problema de regresso. (1985, p. 77)

Em BonJour (2006) não há uma argumentação clara e direta para a tese de que há tal compreensão de ajuste em nossa experiência sensorial, que seria o "conveniente termo médio". Após ter sua posição questionada, BonJour (2006) não nos oferece uma explicação melhor, mas parece apenas limitar-se a repeti-la, enfatizando que, se ela existe, seria capaz de superar o problema do regresso epistêmico sem cair presa do dilema de Sellars, e que é "intuitivamente óbvio" que ela existe. Aquilo que antes (BonJour, 1985) era questionável, obscuro, artificial e falso, passa a ser (BonJour, 1999, 2003, 2006) simples e óbvio, mas não encontramos nenhum rastro de razões que nos conduzam da primeira posição a outra.

\section{Conclusão: uma figura ambígua?}

Podemos ver que a nova postura epistemológica de BonJour representa uma drástica ruptura com suas antigas concepções em epistemologia. O que antes aparecia como obscuro, duvidoso, inconvincente, errado e até impossível, passou a ser visto como possível, simples e intuitivamente óbvio. Sua proposta

\begin{tabular}{|c|c|c|c|c|c|}
\hline intuitio & $\begin{array}{c}\text { ISSN } \\
1983-4012\end{array}$ & Porto Alegre & Vol.8 $-\mathrm{N}^{\circ} .2$ & $\begin{array}{c}\text { Dezembro } \\
2015\end{array}$ & p.94-113 \\
\hline
\end{tabular}


fundacionista é bastante obscura e não é possível encontrar em seus novos trabalhos um argumento claro e decisivo que rebata críticas como as de Bergman (2006) ${ }^{11}$ e que nos leve a crer que o BonJour fundacionista seria capaz de superar as críticas do antigo BonJour coerentista. Toda a argumentação utilizada por aquele seria rejeitada como inválida e inapta por este. Mas alguma "revolução" no pensamento de BonJour ocorreu.

Thomas Kuhn, em A estrutura das revoluções científicas (1962, cap. 9), afirma que mudanças de paradigma nas ciências naturais podem ser entendidas por analogia à mudança na forma (Gestalt) visual que ocorre na apreciação de figuras ambíguas, como a do pato-coelho, da qual ou vemos o pato ou vemos o coelho, mas não ambos simultaneamente. Aquele que pretende valer-se das pretensas orelhas do coelho como indício de que a figura pato-coelho representa um coelho não convencerá aquele que não vê orelhas em lugar algum, mas apenas o bico do pato, e vice-versa. Mudanças de paradigma poderiam também implicar que o que é "visto" como indício da efetividade de determinada teoria científica, nem sequer esteja disponível em um paradigma concorrente. A análise comparativa que fizemos entre as posições do BonJour coerentista e do fundacionista nos deixa tentados a flertar com a hipótese de que tais mudanças de paradigma, como descritas por Kuhn, também podem ocorrer em filosofia. Como no caso da figura do pato-coelho, podemos encontrar na obra de BonJour a figura ambígua do fundacionista-coerentista. O BonJour fundacionista, pressupondo que seja possível, quer encontrar um caso de justificação nãoinferencial que escape às garras do dilema de Sellars. O BonJour coerentista, pressupondo sua impossibilidade, rejeita qualquer alternativa não-inferencial de justificação. BonJour já viu a figura fundacionista-coerentista das duas perspectivas possíveis, mas não o pode fazer simultaneamente, pois ver um aspecto de uma figura ambígua implica não ver o outro. Assim, concepções que antes pareciam obscuras, artificiais e impossíveis da perspectiva coerentista, agora, da perspectiva fundacionista parecem não só possíveis, mas “intuitivamente óbvias" a ponto de não carecerem de muitas razões a seu favor. Já a crítica que agora é vista como superada, antes parecia definitiva, pois, como BonJour costumava alegar,

[...] qualquer tentativa desse gênero é fundamentalmente equivocada e intrinsecamente sem esperança. Pois está claro, sob reflexão, que é uma e a mesma característica de um estado cognitivo, a saber, seu conteúdo assertivo ou ao menos representacional, que permite a ele conferir justificação a outros estados e também cria a necessidade para ele mesmo de ser justificado - assim tornando impossível em princípio separar esses dois aspectos. Não há nenhum benefício em se introduzir estados quase-cognitivos ou semi-judicativos na tentativa de justificar crenças empíricas básicas posto que, seja qual for a extensão de justificação que tal estado seja capaz de conferir, ele terá na mesma extensão necessidade de justificação. (1985, p. 78)

\footnotetext{
${ }^{11}$ Etcheverry (2011) também avalia as críticas de Bergman (2006) a BonJour e conclui que BonJour não dá uma resposta satisfatória à ameaça posta pelo dilema de Sellars e que sua posição é inegavelmente obscura.
}

\begin{tabular}{|c|c|c|c|c|c|}
\hline intuitio & $\begin{array}{c}\text { ISSN } \\
1983-4012\end{array}$ & Porto Alegre & Vol.8 $-\mathrm{N}^{\circ} .2$ & $\begin{array}{c}\text { Dezembro } \\
2015\end{array}$ & p.94-113 \\
\hline
\end{tabular}


Porém, devemos evitar especulações aqui. Não pretendemos afirmar que BonJour não tenha suas razões para defender o fundacionismo em epistemologia, mas apenas que as razões que nos oferece agora não parecem boas o suficiente para superar as críticas que ele mesmo endossava em sua época de coerentista. Embora o BonJour fundacionista reconheça a importância da crítica sellarsiana e a necessidade que qualquer posição fundacionista em epistemologia tem de lidar com ela, não encontramos, de sua parte, nenhuma resposta clara, direta e convincente nessa direção. Desse modo, em detrimento do que BonJour atualmente defende, nos resta concordar com o antigo BonJour coerentista e afirmar que, ao que parece, "o dado é de fato um mito" $(1985, \text { p. } 79)^{12}$.

\section{Referências}

BERGMANN, M. “BonJour's dilemma”. Philosophical Studies, v. 131, 2006. pp. 679-693. http://dx.doi.org/10.1007/s11098-005-2111-1

BONJOUR, L.The structure of empirical knowledge. Cambridge: Harvard University Press. 1985. . "A dialética do fundacionalismo e coerentismo". In: GRECO, J. \& SOSA, E. (Orgs.). Compêndio de epistemologia. São Paulo: Loyola, 2008. pp. 191-229.

. "The dialectic of foundationalism and coherentism". In: GRECO, J. \&SOSA, E. (Eds.). The Blackwell guide to epistemology. Malden: Blackwell, 1999a. pp. 117-142.

.Foundationalism and the external world". Philosophical Perspectives, v. 13, 1999b. pp. 229-249,

."Toward a defense of empirical foundationalism". In: De PAUL, M. (Ed.). Resurrecting oldfashioned foundationalism. Oxford: Rowman \& Littlefield, 2001. pp. 21- 38.

$2115-\mathrm{x}$

. "Replies". Philosophical Studies, v. 131, 2006. pp. 743-759. http://dx.doi.org/10.1007/s11098-005-

BONJOUR, L. \& SOSA, E. Epistemic justification: internalism vs. externalism, foundations vs. virtues. Malden: Blackwell Publishers. 2003.

BRANDOM, R.Making it explicit.Cambridge, Mass.: Harvard University Press. 1994.

DAVIDSON, D. "A Coherence theory of truth and knowledge". In: LEPORE, E. (Ed.). Truth and interpretation: perspectives on the philosophy of Donald Davidson. Oxford: Blackwell, 1986. pp. 307-19.

ETCHEVERRY, K. "O fundacionismo internalista de BonJour e seus críticos". Kinesis, v. 5, 2011. pp. 298308.

ICHIKAWA, J. \& STEUP, M. “The analysis of knowledge”. In: ZALTA, E. (Ed.). The Stanford encyclopedia of philosophy (Fall 2013 edition).2012. Disponível em: <http://plato.stanford.edu/archives/fall2013/entries/knowledge-analysis/>. Acesso em: 20 jan. 2014.

KUHN, T. A estrutura das revoluções científicas. Trad. por Beatriz V. Boeira e Nelson Boeira. São Paulo: Perspectiva, 1982. Original publicado em 1962.

McDOWELL, J.Mente e mundo. Trad. Por João V. G. Cuter. São Paulo: Ideias \& Letras, 2005. Original publicado em 1994.

ROSENTHAL, D. “Two concepts of consciuousness". Philosophical studies. vol. 94. 1986. pp. 329-59. http://dx.doi.org/10.1007/BF00355521

RORTY, R. Philosophy and the mirror of nature. Princeton: Princeton University Press.1979.

SELLARS, W. Empirismo e filosofia da mente. Trad. por Sofia A. Stein. Petrópolis: Vozes, 2008. Original publicado em 1956.

.The structure of knowledge". In: CASTAÑEDA, H. (Ed.). Action, knowledge, and reality. Indianapolis: Boobs-Merrill, 1975. pp. 295-347.

\footnotetext{
${ }^{12}$ Gostaria de agradecer ao revisor anônimo pelas críticas bastante pontuais e pela sugestão de alternativas traduções visando uma melhor apresentação da posição de BonJour.
}

\begin{tabular}{|c|c|l|l|c|c|}
\hline intuitio & $\begin{array}{c}\text { ISSN } \\
1983-4012\end{array}$ & Porto Alegre & Vol.8 $-\mathrm{N}^{\mathrm{o}} .2$ & $\begin{array}{c}\text { Dezembro } \\
2015\end{array}$ & p.94-113 \\
\hline
\end{tabular}


SCHLICK, M. "Facts and propositions". Analysis, v. 2, 1934-35. pp. 65-70.

http://dx.doi.org/10.1093/analys/2.5.65

Recebido em: 10/09/2014

Aprovado para a publicação em: 03/12/2015

\begin{tabular}{|c|c|l|l|c|c|}
\hline intuitio & $\begin{array}{c}\text { ISSN } \\
1983-4012\end{array}$ & Porto Alegre & Vol. $8-\mathrm{N}^{\circ} .2$ & $\begin{array}{c}\text { Dezembro } \\
2015\end{array}$ & p.94-113 \\
\hline
\end{tabular}

